\title{
Dealing with cost-push inflation in Latin America: multi-causality in a context of increased openness and commodity price volatility*
}

\author{
Martín Abeles \\ Economic Commission for Latin America and the Caribbean (ECLAC), United Nations, and Universidad \\ Nacional de San Martín (UNSAM), Argentina

\section{Demian Panigo} \\ Researcher, CITRA-CONICET/Universidad Metropolitana para la Educación y el Trabajo, Argentina, and \\ Professor of Economics, Universidad Nacional de la Plata and Universidad Nacional de Moreno, Argentina
}

\begin{abstract}
Despite recognizing the exogenous, cost-push nature of recent inflationary pressures in Latin America, plus the difficulties faced by monetary authorities in dealing, under such circumstances, with internal and external disequilibria simultaneously, intellectual attention in policy circles remains focused on demand-side issues and policy instruments. This paper develops an eclectic model that has the potential to nest demand-side elements, but focuses on cost-push factors - distributional conflict and propagation mechanisms - as typically addressed by the post-Keynesian-structuralist tradition. In addition to shedding some light on the nature of inflationary pressures as experienced in Latin American countries during the recent commodity boom - in particular South American commodity exporting economies - the paper's main goal is to portray the policy and instrumental trade-offs faced by policy-makers themselves. By bringing unconventional policy devices into the model (such as direct interventions in commodity markets), we hope to broaden the scope of the conventional macroeconomic policy instruments.
\end{abstract}

Keywords: cost-push inflation, alternative exchange-rate regimes, decoupling instruments, Latin America, agflation, commodity prices

JEL codes: $E 31, F 31, D 33$

\section{INTRODUCTION}

The post-Keynesian-structuralist tradition has consistently warned policy-makers and academic economists about the historical nature of their subject matter. From a postKeynesian-structuralist perspective, no single model is appropriate for all developing

* A preliminary version of this paper was presented at 'Structuralism, development and international institutions. A conference in honor of Lance Taylor,' held at the New School for Social Research, New York, 14 October 2011. We thank participants for their comments, in particular Laura Carvalho. The authors would also like to thank the two anonymous referees for their valuable and useful comments and suggestions. The usual disclaimer applies. 
countries because their structures differ; not only at the economic, but also at the political, sociological, and even at the cultural level.

When it comes to formalizing economic phenomena, the post-Keynesianstructuralist approach puts emphasis on the need to construct models appropriate to specific institutional and geographical constraints (Taylor 1983; 1988), including social practices or 'rules of the game' and actual economic linkages as found in the real world, particularly with regard to developing economies. Macroeconomics must therefore start from the interpretation of the relevant structures and economic linkages in each particular case, including the institutional setting of the problem in question.

Post-Keynesian-structuralist macroeconomics is not only inductive (that is, historical, institutional), but also pragmatic in nature, in that it seeks to relate theoretical problems to concrete policy concerns. With this pragmatic motivation in mind, this paper intends to capture the difficulties many Latin American countries have faced in recent years in coping with the inflationary pressures caused by rising and increasingly volatile international commodity prices. We develop an eclectic model ${ }^{1}$ that has the potential to nest demand-side elements while focusing on cost-push factors - international commodity prices, distributional conflict and propagation mechanisms - as addressed by the post-Keynesian-structuralist tradition, with the aim of identifying the institutional and/or policy factors (for example, monetary-cum-exchange-rate regimes) as well as certain structural features (for example, the weight of food in consumption baskets, whether a country is a net importer or exporter of food stables, etc.) that explain the different speed and extent of pass-through effects in different cases.

There is a prominent post-Keynesian-structuralist theoretical and empirical literature on inflation, including on the Latin American case, which combines balance-ofpayments constraints with distributional conflicts and indexation schemes, and has made up the foundations of much macroeconomic reasoning for generations of Latin American macroeconomists (Sunkel 1958; Seers 1962; Olivera 1967; 1973; Frenkel 1984; Vernengo 2003).

In this paper, in addition to shedding some light on the nature of inflationary pressures as experienced in Latin American countries during the recent commodity boom, in particular South American commodity-exporting economies, our chief goal is to portray the policy and instrumental trade-offs faced by policy-makers themselves. By bringing unconventional policy devices into the model itself (such as direct interventions in commodity markets) we hope to broaden the scope of the conventional macroeconomic policy instruments - not only as regards the orthodox, but also the structuralist toolkit.

The paper is organized as follows. Section 2 elaborates on the underlying motivation, Section 3 presents the baseline model and four (policy-related) different variations, and Section 4 concludes.

\section{THE COMMODITY BOOM IN THE 2000s AND THE STANDARD POLICY RESPONSE}

After the dip inflicted by the Great Recession in 2009, most agricultural prices resumed their 2003-2008 escalating path and - even after a slight reversal in 2013

1. For a concise distinction between mono- and multi-causal or 'eclectic' theories of inflation, see Smithin (2011). 
and evidence that the commodity super-cycle may be coming to an end - have remained at historically high levels. Food price volatility also increased during the course of the boom years; in the second half of 2008, volatility attained its highest levels since the beginning of the 1970s (ECLAC 2011a).

The discussion as to what has caused the recent upward trend and heightened volatility in agricultural prices has to some extent been open hitherto. Some point to structural factors (fundamentals) related to supply and demand of food, including changing patterns of world demand; others to climate change and its ever more erratic impact on supply; while others stress the mounting role of speculation with commodities, particularly the interpenetration of the agricultural, financial, and energy markets. ${ }^{2}$

Despite discrepancies in opinion, everyone seems to agree that the combination of rising prices and especially higher volatility is here to stay. This entails a serious challenge for policy-makers, especially to those brought up in the orthodox tradition, who are not used to dealing with cost-push inflation in a systematic manner. Standard advice points to accommodating first-round effects of food and other similar price swings (for example, energy) on the consumer price index but not second-round effects, which should be kept strictly under control. Take, for instance, the following statements by the Bank of International Settlements, published in June 2011:

Soaring commodity prices have ... raised concerns about a significant increase in underlying inflation via second-round effects. There are clear signs of mounting wage pressures in some major emerging market economies ... . Dwindling economic slack and persistent inflation in these countries have been pushing up wage demands. (BIS 2011, p. 56)

Against this backdrop, central banks must remain highly alert to a buildup of inflationary pressures. They should do so even if the evidence may seem at odds with conventional estimates of domestic economic slack and domestic wage developments. Vigilance and a timely tightening of monetary policy in both emerging market and advanced economies will be needed to maintain well anchored inflation expectations, preserve a low-inflation environment globally and reinforce central banks' inflation fighting credibility. (ibid., p. 60).

The following statement by the IMF, published in April 2011, points in a similar direction:

The challenge for many emerging and some developing economies is to ensure that present boom-like conditions do not develop into overheating over the coming year. Inflation pressure is likely to build further as growing production comes up against capacity constraints, with large food and energy price increases, which weigh heavily in consumption baskets, motivating demands for higher wages. Real interest rates are still low and fiscal policies appreciably more accommodative than before the crisis. Appropriate action differs across economies, depending on their cyclical and external conditions. However, a tightening of macroeconomic policies is needed in many emerging economies. (IMF 2011a, p. 5)

It follows that in the realm of conventional macroeconomic wisdom there seems to exist no valid policy instrument to deal with cost-push inflationary pressures other than those associated with the prevention of second-round effects. This means keeping claims for nominal wage improvements in check - via a slowdown in overall economic activity - so that rising costs do not spread through non-tradables and end up affecting underlying (or core) inflation. Of course, this may imply a need to allow

2. For a more detailed discussion see UNCTAD (2011). 
for pervasive real wage cutbacks and, to the extent that food consumption weighs more heavily in the consumption baskets of the poor, the likely worsening of income distribution. $^{3}$

In line with this type of judgment, monetary authorities in many Latin American countries have responded to the rise in international commodity prices by tightening monetary policy, thus raising interest rates and causing a nominal appreciation of their currencies. This was the case not only in the 2007-2008 surge but also, albeit more moderately, during the most recent 2010-2011 rise (ECLAC 2011b).

Note, however, that in Latin America, due to relatively low financial intermediation (with the probable exception of Chile), the credit channel is rather weak compared with the exchange-rate channel. As a result, in Latin America aggregate demand has always been rather insensitive to changes in interest rates. ${ }^{4}$ Hence, in practice monetary policy in Latin America has operated chiefly via the exchange-rate channel, by reducing the domestic value of tradable goods (a first-round effect), including food staples, rather than by easing the pace of aggregate demand (a second-round effect). This mechanism turned particularly important in the presence of rising international commodity prices (Abeles and Borzel 2010).

Figure 1 shows the offsetting role played by nominal exchange-rate appreciation vis-à-vis surging commodity prices as headline inflation went up in Brazil, Chile, Colombia, Mexico, Peru, and Uruguay. ${ }^{5}$ In particular, Brazil, Colombia, and Uruguay have resorted to hard-line currency appreciation in order to keep inflationary pressures in check. ${ }^{6}$

The tendency of exchange rates to appreciate not only resulted from rising domestic interest rates but also from falling interest rates in advanced economies. In the early stages of the commodity boom, the improvement in terms of trade also contributed to the appreciation of nominal exchange rates, especially in South American primary exporting economies. In fact, a striking feature of the commodity boom period is, after an initial improvement, the sequence of rising terms of trade and deteriorating currentaccount balances, particularly in $2010 .^{7}$

From the point of view of price stabilization, it may make sense to concentrate efforts on first-round effects associated with rising international commodity prices in view of the fact that commodity prices - particularly food prices - tend to have stronger and longer-lasting effects on inflation in economies with high food shares

3. In all fairness, the IMF, as well as other international organizations, do acknowledge the impact of rising commodity prices on the poor (particularly staple food prices) and therefore recommend the development of new targeted safety nets or the strengthening of existing ones. 4. See Barbosa (2008), Frenkel (2008), and Galindo and Ros (2008).

5. With the exception of Uruguay, all of these countries have formally adopted inflationtargeting regimes.

6. This does not imply that monetary authorities in these countries have adopted free-floating exchange-rate regimes. Indeed, intervention in currency markets abounds in the region, even in these particular cases, mainly to moderate short-term volatility, but also to prevent 'excessive' currency appreciation, especially in times of abundant international liquidity.

7. These events point to the potential incongruities faced by economies with formal inflation targets and foreign sector constraints. Perez Caldentey and Vernengo (2013) argue that the justification for inflation-targeting regimes is derived from a closed-economy setting which is not representative of the countries that have actually adopted inflation-targeting frameworks, where concerns over the evolution of the external sector and the exchange rate in practice frequently override concerns over internal price stabilization. 

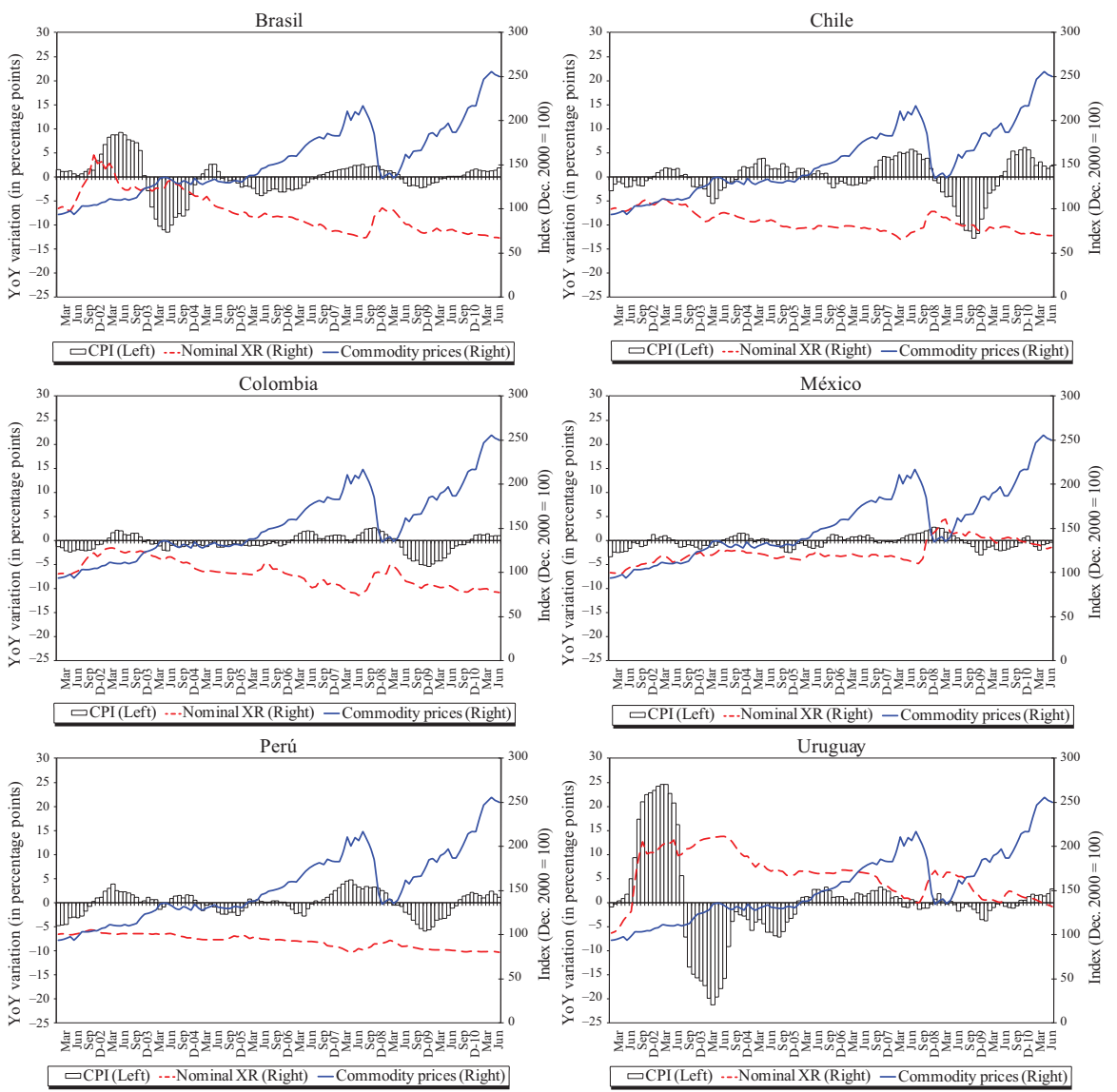

Figure 1 CPI, nominal exchange rates, and commodity prices, January 2002 to June 2011

in the consumption basket, as is the case in most developing countries. ${ }^{8}$ But, as we know from the development literature, resorting to exchange-rate appreciation as an anti-inflationary device comes at the medium-term cost of Dutch disease-type symptoms and destabilizing foreign-debt dynamics.

In part as a reaction to this type of concern, especially in the presence of marked exchange-rate misalignments in some prominent semi-industrialized economies, the IMF has somewhat relaxed its otherwise inflexible, doctrinaire position against capital controls, so that by raising interest rates monetary authorities do not exacerbate exchange-rate appreciation. But despite recognizing the difficulties faced by monetary authorities in many developing countries in dealing with internal and external disequilibria simultaneously, attention has not shifted to the eventual implementation of other

8. According to a recent IMF survey, the median food share is 17 percent in advanced economies and 31 percent in emerging and developing economies (IMF 2011b). 
policies that may be of assistance in neutralizing or smoothing-out first-round effects other than allowing for the 'side effect' of exchange-rate appreciation - but has largely remained focused on the search for alternative contractionary devices to deal with second-round effects, typically fiscal (IMF 2011a).

According to standard advice, in order to prevent rising international commodity prices from having an impact on core inflation, wage demands (which tend to push non-tradable prices upwards) should be kept under control. To achieve this goal, overall economic activity needs to be cooled off. For that purpose, the customary policy tool, contractionary monetary policy, has proven less and less appropriate, as it tends to exacerbate the underlying tendency of exchange rates to appreciate, with negative effects on non-traditional tradable sector profitability.

To be sure, a slower pace for aggregate demand makes fighting inflation much easier. But if the main triggering factor does not lie in domestic demand but pertains to rising international commodity prices, particularly food prices, tackling secondround effects alone via conventional contractionary policies seems ineffective and, most importantly, unnecessarily costly from a social point of view. ${ }^{9}$ Fighting inflation via exchange-rate appreciation is likely to be more effective, but might be even worse due to the above-mentioned medium-term costs. We elaborate on these trade-offs using the model presented below.

\section{THE MODEL}

The model developed in this section is constructed on the simplifying assumption that international commodity prices, aggregate demand, and GDP are exogenous variables, as in part of the structuralist literature (for example, Olivera 1967; Canavese 1982). The novelty in our model is that (i) we seek to include non-conventional macroeconomic policy instruments (for example, flexible import tariffs or export duties for wage goods, subsidies, and price regulation in public services, etc.) and (ii) we deal with five different sectors, instead of the more familiar two-sector models of the structuralist tradition.

\subsection{The baseline model}

Domestic inflation $\pi_{t}$ is a weighted average of inflation in the tradable and nontradable goods ( $\pi_{t}^{t}$ and $\pi_{t}^{n t}$, respectively), with three varieties in the case of tradable goods and two in the case of non-tradable goods.

The three different tradable goods are: wage goods $(w)$; other 'non-edible' primary goods $(o p)$; and manufactures $(m)$. We assume the country is a semi-industrialized economy, with an emerging but underdeveloped manufacturing sector, but originally specialized in the production of either $w$ or $o p$. We also assume that the country is a price-taker in all markets and that international prices of $w, o p$, and $m$ grow at the exogenous rates $\bar{\rho}, \bar{\varphi}$, and $\bar{\psi}$, respectively:

$$
\begin{aligned}
\pi_{t}^{w *} & =\bar{\rho} \\
\pi_{t}^{o p *} & =\bar{\chi} \\
\pi_{t}^{m *} & =\bar{\psi},
\end{aligned}
$$

9. Arestis and Sawyer (2013) make a similar point. 
where $\pi_{t}^{\omega *}$ stands for the international inflation rate of wage goods (food staples), $\pi_{t}^{o p *}$ for the international inflation rate of other primary good (minerals and oil), and $\pi_{t}^{m *}$ for the international inflation rate of manufactures.

The domestic prices of tradable goods evolve according to their international price, the nominal exchange-rate variation ner (domestic currency per unit of foreign currency) and a policy variable we have dubbed the 'decoupling coefficient' ( $\lambda^{i}$, for $i=w, o p$, and $m$ ), as in equations (4) to (6) below:

$$
\begin{aligned}
& \pi_{t}^{w}=\pi_{t}^{w *}+n e r_{t}+\lambda^{w} \\
& \pi_{t}^{o p}=\pi_{t}^{o p *}+n e r_{t}+\lambda^{o p} \\
& \pi_{t}^{m}=\pi_{t}^{m *}+n e r_{t}+\lambda^{m} .
\end{aligned}
$$

The decoupling coefficients $\lambda^{w}, \lambda^{o p}$ and $\lambda^{m}$ indicate the extent to which the variations in import tariffs, export duties, domestic taxes, or subsidies, etc., affect the domestic price variations of wage goods, other primary goods, and manufactures, respectively. For example, in the case of an import tariff on wage goods, a reduction in $\lambda^{w}$ reduces $\pi_{t}^{w}$ for a given change in international food prices $\pi_{t}^{w *}$ and a given change in the nominal exchange rate $n e r_{t}$.

Equation (7) summarizes the domestic inflation rate of tradable goods $\pi_{t}^{t}$ :

$$
\pi_{t}^{t}=a \pi_{t}^{w}+b \pi_{t}^{o p}+c \pi_{t}^{m} \quad(\text { with } a+b+c=1)
$$

where $a, b$, and $c$ are consistent with the weights of $w, o p$, and $m$ goods in this group.

Before moving on to non-tradables, let us define the wage function, which is most important to the structuralist tradition and its approach to inflation. Equation (8) below assumes that wages in all five sectors (the three tradable sectors described above plus the two non-tradable sectors to be described shortly, a regulated $r n t$ and an unregulated unt non-tradable sector) grow at the same pace. This pace is determined by a leading union. We assume this union belongs to either one of the two traditional exporting sectors ( $w$ or $o p$ ). Equation (8) also includes an 'adaptive expectations' or inertial coefficient $\varepsilon$, linked to the inflation rate in $t-1$, and a distributional coefficient $\kappa$, which indicates the extent to which productivity growth in the leading union's sector is passed on to workers:

$$
w_{t}^{w}=w_{t}^{o p}=w_{t}^{m}=w_{t}^{u n t}=w_{t}^{r n t}=w_{t}=\varepsilon \pi_{t-1}+\kappa \overline{\phi^{l}},
$$

where $\phi^{l}$ stands for productivity growth in the leading sector.

Let us now turn to the non-tradable sector. As mentioned above, we split this sector up into a regulated and an unregulated (or competitive) sub-sector. In the latter, prices evolve according to a Kaleckian price equation where the sectoral inflation rate is a function of average variable costs and unit profit margins. The evolution of average variable costs in turn depends on the variation of unit labor costs $\left(w_{t}^{\text {unt }}-\overline{\phi^{u n t}}\right)$, the tradable inputs' inflation rate $\pi_{t}^{t}$, and the non-tradable inputs' inflation rate $\pi_{t}^{n t}$, in proportion to their respective $(d, e, f$, and $g$ ) weights in the gross value of production. Inflation in unregulated non-tradable sectors also depends on the variation of unit profit margins $\tau$, also in proportion to its weight in the gross value of production. We assume unit profit margins remain unchanged throughout the cycle, but they 
could be positively related to output growth, which is also exogenously determined in the present model.

$$
\pi_{t}^{u n t}=d\left(w_{t}^{u n t}-\overline{\phi^{u n t}}\right)+e\left(\pi_{t}^{t}\right)+f\left(\pi_{t}^{n t}\right)+g \tau .
$$

Prices in the regulated non-tradable sector grow at an exogenous rate $\delta$, which is a policy variable.

$$
\pi_{t}^{r n t}=\delta
$$

Non-tradable inflation is a weighted average of regulated and unregulated nontradable inflations rates:

$$
\pi^{n t}{ }_{t}=h \pi_{t}^{u n t}+(1-h) \pi_{t}^{r n t} \quad(\text { with } 0<h<1)
$$

Headline inflation is the weighted average of domestic tradable and non-tradable inflation:

$$
\pi_{t}=\alpha \pi_{t}^{t}+(1-\alpha) \pi_{t}^{n t}
$$

Equation (13) indicates the change in the markup rate over unit labor costs in the manufacturing sector:

$$
\mu_{t}^{m}=\pi_{t}^{m}-j\left(w_{t}^{m}-\phi^{m}\right) .
$$

This reveals the potential profitability of domestic production of non-traditional tradable goods. The change in the markup rate over unit labor costs in the manufacturing sector $\mu_{t}^{m}$ depends on the domestic inflation rate of manufactured goods $\pi_{t}^{m}$, as determined by equation (6), and on the increase of unit labor costs $j\left(w_{t}^{m}-\phi^{m}\right)$, where $\phi^{m}$ denotes labor productivity growth in the domestic manufacturing sector and $j$ the weight of labor costs in the gross value of manufacturing production.

Equations (14) and (15) represent the distributive conflict, setting the rules of the game with regard to labor productivity growth and its impact on the profit share.

Equation (14) portrays average labor productivity $\phi^{\text {tot }}{ }_{t}$ as a weighted average of labor productivity growth in the five sectors of the economy (with the corresponding weights set in proportion to consumption weights):

$$
\phi^{t o t}{ }_{t}=\alpha a \overline{\phi^{w}}+\alpha b \overline{\phi^{o p}}+\alpha c \overline{\phi^{m}}+(1-\alpha) h \overline{\phi^{u n t}}+(1-\alpha)(1-h) \overline{\phi^{r n t}} .
$$

Combining productivity growth, as represented in (14), with prices and wage determination, as represented in (12) and (8) respectively, equation (15) below arrives at an expected result - namely that the change in the profit share $b_{t}^{\text {tot }}$ is equal to the increase in average labor productivity minus the increase in the real wage.

$$
b_{t}^{t o t}=\pi_{t}+\phi^{t o t}{ }_{t}-w_{t}
$$

Solving (1) through (15) for $\pi_{t}$ we obtain:

$$
\begin{aligned}
\pi_{t}= & \frac{1}{1-f h}\left\{[ h e ( 1 - \alpha ) + \alpha ( 1 - f h ) ] \left[a\left(\bar{\rho}+\lambda^{w}\right)+b\left(\bar{\chi}+\lambda^{o p}\right)+c\left(\bar{\psi}+\lambda^{m}\right)\right.\right. \\
& \left.+n e r]+\left[h(1-\alpha)\left(g \tau+d \kappa \overline{\phi^{l}}-d \overline{\phi^{u n t}}\right)+(1-\alpha)(1-h) \delta\right]\right\} \\
& +\frac{1}{1-f h}\left[(1-\alpha) h d \varepsilon \pi_{t-1}\right] .
\end{aligned}
$$


And as $t \rightarrow \infty$, from equation (16) we get:

$$
\begin{aligned}
\pi_{t}= & \frac{1}{1-f h-[(1-\alpha) h d \varepsilon]}\left\{[ h e ( 1 - \alpha ) + \alpha ( 1 - f h ) ] \left[a\left(\bar{\rho}+\lambda^{w}\right)+b\left(\bar{\chi}+\lambda^{o p}\right)+c\left(\bar{\psi}+\lambda^{m}\right)\right.\right. \\
& \left.+n e r]+\left[h(1-\alpha)\left(g \tau+d \kappa \overline{\phi^{l}}-d \overline{\phi^{u n t}}\right)+(1-\alpha)(1-h) \delta\right]\right\} .
\end{aligned}
$$

If, in addition, we assume that the nominal exchange rate and the 'decoupling coefficients' remain unchanged (that is, $n e r_{t}=\lambda^{i}=0 ; \forall i \in[w, o p, m]$ ) and the stability condition holds $(f h+[(1-\alpha) h d \varepsilon]<1)$, equation (17) boils down to:

$$
\begin{aligned}
\pi^{B A S E} & =\frac{1}{1-f h-[(1-\alpha) h d \varepsilon]}\{[h e(1-\alpha)+\alpha(1-f h)][a(\bar{\rho})+b(\bar{\chi})+c(\bar{\psi})] \\
& \left.+\left[h(1-\alpha)\left(g \tau+d \kappa \overline{\phi^{l}}-d \overline{\phi^{u n t}}\right)+(1-\alpha)(1-h) \delta\right]\right\} .
\end{aligned}
$$

The inflation rate in the baseline model $\pi^{B A S E}{ }_{t}$, with no 'policy action,' will thus be higher: (i) the higher the international inflation rate $([a(\bar{\rho})+b(\bar{\chi})+c(\bar{\psi})]$, including their respective weights in the CPI), as in the Scandinavian structuralist tradition (Maynard and van Ryckeghem 1976); (ii) the stronger the wage resistance, as indicated by the adaptive expectations or inertial coefficient $\varepsilon$; (iii) the larger the share of productivity growth workers take hold of in the leading sector $\left(\kappa \overline{\phi^{l}}\right)$, as this share has a bearing on wage increases in the rest of the economy, particularly in the non-tradable sectors; (iv) the larger the variation of the non-tradable sector's unit profit margin $\tau$; and (v) the larger the growth rate of prices in the regulated non-tradable sector $(\delta)$.

In short, the baseline model states that domestic inflation is determined by international inflation, sectoral productivity growth disparities, distributional conflict, and regulated non-tradable sector prices (for example, utility rates). Note that both $\varepsilon$ and $\tau$ are typically procyclical in practice (that is, they increase with higher capacity utilization), although they are kept exogenous here to keep things simple.

Non-traditional tradable sector profitability is represented in this model by the evolution of the markup rate over unit labor costs in the manufacturing sector, which in the baseline equals:

$$
\begin{aligned}
\mu_{t}^{m, B A S E} & =\bar{\psi}-j \varepsilon\left(\frac{1}{1-f h-[(1-\alpha) h d \varepsilon]}\{[h e(1-\alpha)+\alpha(1-f h)][a(\bar{\rho})+b(\bar{\chi})+c(\bar{\psi})]\right. \\
& \left.\left.+\left[h(1-\alpha)\left(g \tau+d \kappa \phi^{l}-d \overline{\phi^{u n t}}\right)+(1-\alpha)(1-h) \delta\right]\right\}\right)-j\left(\kappa \overline{\phi^{l}}-\phi^{m}\right)
\end{aligned}
$$

Similarly, from (8), (14), (15), and (18) we obtain the variation in the profit share:

$$
\begin{aligned}
b_{t}^{\text {tot, BASE }}= & (1-\varepsilon)\left(\frac{1}{1-f h-[(1-\alpha) h d \varepsilon]}\{[h e(1-\alpha)+\alpha(1-f h)][a(\bar{\rho})+b(\bar{\chi})\right. \\
& \left.\left.+c(\bar{\psi})]+\left[h(1-\alpha)\left(g \tau+d \kappa \overline{\phi^{l}}-d \overline{\phi^{u n t}}\right)+(1-\alpha)(1-h) \delta\right]\right\}\right)+\alpha a \overline{\phi^{w}} \\
& +\alpha b \overline{\phi^{o p}}+\alpha c \overline{\phi^{m}}+\beta h \overline{\phi^{u n t}}+\beta i \overline{\phi^{r n t}}-\kappa \overline{\phi^{l}} .
\end{aligned}
$$

Note in equation (19) that the change in the markup rate over unit labor costs in the manufacturing sector depends, first, on the variation of international manufacturing prices $\bar{\psi}$, but also among other things on the difference between the leading and the manufacturing sector's productivity growth rates. In turn, in equation (20) the change in the overall profit share depends, among other things, negatively on $\varepsilon$ and $\kappa$, an indicator of unions' negotiating strength. 
In what follows we focus on the effects of different exchange-rate regimes and/or direct intervention in commodity markets in the inflation rate, non-traditional tradable sector competitiveness, and income distribution. By dealing with these issues at an analytical level we seek to shed some light on the recent trade-offs faced by policy-makers themselves in the Latin American region, particularly in South America.

We analyse four 'ideal types.' As suggested above, at one end of the spectrum some countries have confronted the rise in international commodity prices essentially via nominal exchange-rate appreciation, a side-effect of standard monetary policy tightening. We deal with this type of situation under Case 1 below. At the other end of the spectrum, other countries have deliberately sought to prevent exchange-rate appreciation (resulting from improving terms of trade, rising domestic prices, and high international liquidity), in order to protect non-traditional tradable industries, ${ }^{10}$ and seem to have been less concerned about inflation. We deal with this type of approach under Case 3 below. Somewhere in the middle, other countries have introduced administrative measures instead of standard monetary policy tightening. This is where 'decoupling' measures play a relevant role. We tackle the effects of this line of attack under Case 2 below. Finally, in Case 4 we deal with the combination of Cases 2 and 3.

\subsection{Case 1: exchange-rate appreciation (inflation-targeting regimes)}

In general, South American countries with formal inflation-targeting regimes have resorted to exchange-rate appreciation as their main anti-inflationary device against rising international commodity prices. In theory, as mentioned earlier, monetary authorities raise interest rates to cool off aggregate demand via the credit channel in order to avert second-round effects that may result from the rise in commodity prices, particularly food staples. But in practice inflation is held back not - or not mainly - due to the contractionary effect of higher interest rates on aggregate demand but due to its costreducing effect on tradable goods in general (recall Figure 1).

In order to represent this type of situation, we keep the baseline model's assumption that $\lambda^{i}=0 ; \forall i \in[w, o p, m]$ but in order to illustrate the characteristic exchange-rate appreciating reaction, the following exchange-rate rule is introduced:

$$
n e r_{t}=-\gamma \bar{\rho} \quad(\text { with } 0 \leq \gamma)
$$

10. The literature favoring this type of policy stance (for example, Frenkel and Ros 2006) maintains that a competitive exchange rate has an expansionary effect on aggregate demand via the increase in profit margins. Accordingly this literature assumes that the positive impact of a more competitive exchange rate on investment and exports outstrips its negative impact on consumption, which results from the ensuing fall in real wages. Empirical evidence seems inconclusive on this. While a recent post-Keynesian publication (Lavoie and Stockhammer 2014) presents data that appear to confirm this view for Latin American countries, there is also empirical evidence with conflicting results (also involving Latin American countries), particularly with regard to the effect of exchange rates on export performance, suggesting a low or insignificant impact of competitive exchange rates on exports (Bernat 2015). Despite this inconclusiveness, in constructing our formal model we take these contentions for granted in order to show that even under these optimistic assumptions (regarding the impact of competitive exchange rates on development) there exist superior exchange-rate-cum-monetary-policy strategies (Panigo and Chena 2011). 
The rule depicted in equation (21) implies that the domestic impact of the increase in international food prices is offset (partially or totally, depending on the magnitude of $\gamma$ ) by the appreciation of the exchange rate. Assuming $t \rightarrow \infty$ and the same stability condition as above (that $f h+[(1-\alpha) h d \varepsilon]<1$ ), we now obtain:

$$
\begin{aligned}
\pi_{t}^{C 1}= & \frac{1}{1-f h-[(1-\alpha) h d \varepsilon]}\{[h e(1-\alpha)+\alpha(1-f h)][(a-\gamma)(\bar{\rho})+b(\bar{\chi})+c(\bar{\psi})] \\
& \left.+\left[h(1-\alpha)\left(g \tau+d \kappa \overline{\phi^{l}}-d \overline{\phi^{u n t}}\right)+(1-\alpha)(1-h) \delta\right]\right\} .
\end{aligned}
$$

For a given rise in international inflation, the resulting inflation rate $\pi_{t}^{C 1}$ in (22) is smaller than the baseline inflation rate $\pi^{B A S E}{ }_{t}$ in (18); how much smaller depends, of course, on the magnitude of $\gamma$.

The anti-inflationary achievement of this approach comes at a well-known cost: the loss of competitiveness of non-traditional tradable industries, personified here by the manufacturing sector. Under the exchange-rate rule given by equation (21) the manufacturing sector's markup rate over unit labor costs evolves according to the following expression:

$$
\begin{aligned}
\mu_{t}^{m, C 1}= & \bar{\psi}-\gamma \bar{\rho}-j \varepsilon\left(\frac{1}{1-f h-[(1-\alpha) h d \varepsilon]}\{[h e(1-\alpha)+\alpha(1-f h)][(a-\gamma)(\bar{\rho})+b(\bar{\chi})\right. \\
& \left.\left.+c(\bar{\psi})]+\left[h(1-\alpha)\left(g \tau+d \kappa \bar{\phi}^{l}-d \overline{\phi^{u n t}}\right)+(1-\alpha)(1-h) \delta\right]\right\}\right)-j\left(\kappa \overline{\phi^{l}}-\phi^{m}\right) .
\end{aligned}
$$

It can be shown that $\mu_{t}^{m, C 1}$ is smaller than, or equal to, $\mu_{t}^{m, B A S E}$, but never larger. ${ }^{11}$ The negative effect of exchange-rate appreciation on profitability in the manufacturing sector will be larger the smaller are $j, \varepsilon, \alpha, h, d$, and $e$, and the larger is $f$, with $\lim _{(j \rightarrow 1, \varepsilon \rightarrow 1, \alpha \rightarrow 1, h \rightarrow 1,(d+e) \rightarrow 1)} \Omega \cong 1$ and $\lim _{(j \rightarrow 0, \varepsilon \rightarrow 0, \alpha \rightarrow 0, h \rightarrow 0, f \rightarrow 1)} \Omega \cong 0$. Indeed, when these parameters tend to $0, \Omega$, as defined in footnote 11 , also does, which means that exchange-rate appreciation impact on manufacturing sector prices is not completely offset by the fall in unit labor costs.

As per the effect of exchange-rate appreciation on the profit share, assuming that in the short term employment and productivity growth do not vary, we obtain:

$$
\begin{aligned}
b_{t}^{t o t, C 1}= & (1-\varepsilon)\left(\frac{1}{1-f h-[(1-\alpha) h d \varepsilon]}\{[h e(1-\alpha)+\alpha(1-f h)][(a-\gamma)(\bar{\rho})+b(\bar{\chi})\right. \\
& \left.\left.+c(\bar{\Psi})]+\left[h(1-\alpha)\left(g \tau+d \kappa \overline{\phi^{l}}-d \overline{\phi^{u n t}}\right)+(1-\alpha)(1-h) \delta\right]\right\}\right) \\
& +\alpha a \overline{\phi^{w}}+\alpha b \overline{\phi^{o p}}+\alpha c \overline{\phi^{m}}+\beta h \overline{\phi^{u n t}}+\beta \overline{i \phi^{r n t}}-\kappa \overline{\phi^{l}} .
\end{aligned}
$$

Here, again, it can be shown that $b_{t}^{\text {tot,C1 }} \leq b_{t}^{\text {tot,BASE }}$ means that in the short run currency appreciation leads to a less regressive (or, yet, more progressive) income distribution. But while this is true in the short run, according to the 'new developmentalism' ${ }^{12}$ it need not be true in the medium or long term, as employment generation decelerates or recedes (along with current-account deterioration). In equation (24) this mediumterm scenario may be interpreted as a reduction of $\varepsilon$.

11. For this proof it should be borne in mind that $1 \geq \Omega$, where $\Omega=\left(\frac{[h e(1-\alpha)+\alpha(1-f h)] j \varepsilon}{(1-f h)-[(1-\alpha) h d \varepsilon]}\right)$, that all the parameters fall in the range $(0,1)$, and that in equation (9) $d+e+f+g=1$.

12. See discussion in footnote 10 . 


\subsection{Case 2: selective 'decoupling' (import tariffs, export duties, domestic taxes, subsidies, etc.)}

There are other policy devices that can help decouple domestic from international commodity prices. Different countries have resorted to different administrative instruments depending on their economic and institutional structure. In some cases, import tariffs were reduced in order to reduce the domestic cost of a particular good (for example, sugar in Peru); in others, variable internal taxes on certain essential goods were established, so as to smoothen the domestic effect of volatility in international markets (for example, gasoline in Chile); in others, export duties were increased in tandem with the rise in international commodity prices (for example, agricultural exports in Argentina), so as to reduce the net export price attained by producers and thus diminish the domestic price. In yet other cases, where state-owned enterprises set the market price, domestic prices were smoothened vis-à-vis international prices (for example, oil in Brazil).

Formally, this implies the need to maintain the assumption that $n e r_{t}=\lambda^{m}=0$, but introduce the following policy rules:

$$
\begin{aligned}
\lambda^{w} & =-\gamma \bar{\rho} \\
\lambda^{o p} & =-\omega \bar{\chi} .
\end{aligned}
$$

This means that import tariffs, export duties, specific domestic taxes, etc., which have an effect on the domestic price of commodities, will vary when international commodity prices vary. For example, an import tariff on a particular commodity may be reduced as its international price rises so as to moderate its pass-through to domestic prices, and vice versa. Similarly, an export duty on a particular good may be increased as its international price rises, and vice versa. With this amendment, the reduced form is now:

$$
\begin{aligned}
\pi_{t}^{C 2}= & \frac{1}{1-f h-[(1-\alpha) h d \varepsilon]}\{[h e(1-\alpha)+\alpha(1-f h)][a(1-\gamma)(\bar{\rho})+b(1-\omega)(\bar{\chi}) \\
& \left.+c(\bar{\psi})]+\left[h(1-\alpha)\left(g \tau+d \kappa \overline{\phi^{l}}-d \overline{\phi^{u n t}}\right)+(1-\alpha)(1-h) \delta\right]\right\} .
\end{aligned}
$$

Here, $\pi_{t}^{C 2}$ is also smaller than $\pi_{t}^{B A S E}$ but indeterminate vis-à-vis $\pi_{t}^{C 1}$. If $\omega=0$, so that decoupling operates only on international food prices (and not in other tradable goods), then $\pi_{t}^{C 2}>\pi_{t}^{C 1}$, since $a(1-\gamma)(\bar{\rho})>(a-\gamma)(\bar{\rho})$. More generally, the comparison between $\pi_{t}^{C 2}$ and $\pi_{t}^{C 1}$ depends on the following inequality: $\bar{\rho} \lesseqgtr \omega \frac{\bar{\chi}}{\gamma(1-a)}$. The difference between $\pi_{t}^{C 2}$ and $\pi_{t}^{C 1}$ will be larger, the higher is international food inflation $(\bar{\rho})$ vis-à-vis other primary products $(\bar{\chi})$ and the larger the food decoupling coefficient $(\gamma)$ vis-à-vis the other primary goods' decoupling coefficient $(\omega)$. In both cases, $\pi_{t}^{C 2}$ and $\pi_{t}^{C 1}$, the outcome is smaller than $\pi_{t}^{B A S E}$.

However, as opposed to the previous case, with selective decoupling the manufacturing sector's markup rate over unit labor costs does not decline so much:

$$
\begin{aligned}
\mu_{t}^{m, C 2}= & \bar{\psi}-j \varepsilon\left(\frac{1}{1-f h-[(1-\alpha) h d \varepsilon]}\{[h e(1-\alpha)+\alpha(1-f h)][a(1-\gamma)(\bar{\rho})+b(1-\omega)(\bar{\chi})\right. \\
& \left.\left.+c(\bar{\psi})]+\left[h(1-\alpha)\left(g \tau+d \kappa \overline{\phi^{l}}-d \overline{\phi^{u n t}}\right)+(1-\alpha)(1-h) \delta\right]\right\}\right)-j\left(\kappa \overline{\phi^{l}}-\phi^{m}\right) .
\end{aligned}
$$


Compared to equation (19), $\mu_{t}^{m, C 2}>\mu_{t}^{m, B A S E}$, since $\left(\frac{1}{1-f h-[(1-\alpha) h d \varepsilon]}\{[h e(1-\alpha)+\right.$ $\left.\left.\alpha(1-f h)][a(1-\gamma)(\bar{\rho})+b(1-\omega)(\bar{\chi})+c(\bar{\psi})]+\left[h(1-\alpha)\left(g \tau+d \kappa \overline{\phi^{l}}-d \overline{\phi^{u n t}}\right)+(1-\alpha)(1-h) \delta\right]\right\}\right)<$ $\left(\frac{1}{1-f h-[(1-\alpha) h d \varepsilon]}\left\{[h e(1-\alpha)+\alpha(1-f h)][a(\bar{\rho})+b(\bar{\chi})+c(\bar{\psi})]+\left[h(1-\alpha)\left(g \tau+d \kappa \overline{\phi^{l}}-d \overline{\phi^{u n t}}\right)\right.\right.\right.$ $+(1-\alpha)(1-h) \delta]\})$. As we know $\mu_{t}^{m, B A S E}>\mu_{t}^{m, C 1}$, then $\mu_{t}^{m, C 2}>\underset{\mu}{t m, C 1}$ also.

With regard to income distribution, the comparison between Cases 1 and 2 is again indeterminate a priori. The change in the profit share $b_{t}^{\text {tot }}$ in the case of selective decoupling is:

$$
\begin{aligned}
b_{t}^{t o t, C 2}= & (1-\varepsilon)\left(\frac{1}{1-f h-[(1-\alpha) h d \varepsilon]}\{[h e(1-\alpha)+\alpha(1-f h)][a(1-\gamma)(\bar{\rho})+b(1-\omega)(\bar{\chi})\right. \\
& \left.\left.+c(\bar{\psi})]+\left[h(1-\alpha)\left(g \tau+d \kappa \overline{\phi^{l}}-d \overline{\phi^{u n t}}\right)+(1-\alpha)(1-h) \delta\right]\right\}\right)+\alpha a \overline{\phi^{w}}+\alpha b \overline{\phi^{o p}} \\
& +\alpha c \overline{\phi^{m}}+\beta h \overline{\phi^{u n t}}+\beta \overline{\phi^{r n t}}-\kappa \overline{\phi^{l}} .
\end{aligned}
$$

It can be shown that $b_{t}^{\text {tot }, C 2} \leq b_{t}^{\text {tot,BASE}}$, but its magnitude is indefinite with respect to $b_{t}^{\text {tot }, C 1}$. In broad terms, $b_{t}^{\text {tot }, C 2} \leq b_{t}^{\text {tot, } C 1}$ if $\bar{\rho} \leq \omega \frac{\bar{\chi}}{\gamma(1-a)}$; an unlikely observation in the region.

\subsection{Case 3: real exchange-rate targeting}

This case could be dubbed the 'new developmentalism' case, as it seeks to preserve external price competitiveness in the non-traditional tradable sector. Formally this can be represented in our framework by going back to the assumptions and equations used in Case 1 (exchange-rate appreciation) but modifying equation (21) by the following rule:

$$
n e r_{t}=-\bar{\psi}+j\left(w_{t}^{m}-\phi^{m}\right)
$$

This amounts to setting a nominal exchange rate (crawling peg) that ensures no loss of competitiveness to the non-traditional manufacturing sector. ${ }^{13}$ Given $\bar{\psi}$ and $\phi^{m}$, the nominal exchange rate will thus rise as $w_{t}^{m}$ rises, pushed by productivity in the leading (exporting) sector. In this case, the model's reduced form looks like this:

$$
\begin{aligned}
\pi_{t}^{C 3}= & \frac{1}{1-f h}\left\{[h e(1-\alpha)+\alpha(1-f h)][a \bar{\rho}+b \bar{\chi}+c \bar{\psi}]+\left[h(1-\alpha)\left(g \tau+d \kappa \overline{\phi^{l}}-d \overline{\phi^{u n t}}\right)\right.\right. \\
& +(1-\alpha)(1-h) \delta]\}+\frac{1}{1-f h}\left[(1-\alpha) h d \varepsilon \pi_{t-1}\right]+\frac{1}{(1-f h)}\{j[h e(1-\alpha) \\
& \left.+\alpha(1-f h)]\left[\left(\kappa \overline{\phi^{l}}-\overline{\phi^{m}}\right)-\frac{\bar{\psi}}{j}\right]\right\}+\frac{1}{(1-f h)}\left\{[h e(1-\alpha)+\alpha(1-f h)] j \varepsilon \pi_{t-1}\right\} .
\end{aligned}
$$

As $t \rightarrow \infty$ and the new stability condition holds $(1>f h+[(1-\alpha) h d \varepsilon]+j \varepsilon[h e(1-\alpha)+$ $\alpha(1-f h)]$ ), equation (31) converges to:

$$
\begin{aligned}
\pi_{t}^{C 3}= & \frac{1}{1-f h-[(1-\alpha) h d \varepsilon]-j \varepsilon[h e(1-\alpha)+\alpha(1-f h)]}\{[h e(1-\alpha) \\
& +\alpha(1-f h)][a \bar{\rho}+b \bar{\chi}+c \bar{\psi}]+\left[h(1-\alpha)\left(g \tau+d \kappa \overline{\phi^{l}}-d \overline{\phi^{u n t}}\right)\right. \\
& \left.+(1-\alpha)(1-h) \delta]+\left(j[h e(1-\alpha)+\alpha(1-f h)]\left[\left(\kappa \overline{\phi^{l}}-\overline{\phi^{m}}\right)-\frac{\bar{\psi}}{j}\right]\right)\right\} .
\end{aligned}
$$

13. It implies the additional assumption that non-labor costs do not vary significantly. 
Comparing equation (32) with (18), it follows that when $\bar{\psi}$ is not too high (a reasonable assumption), so that the term $\left(j[h e(1-\alpha)+\alpha(1-f h)]\left[\left(\kappa \overline{\phi^{l}}-\overline{\phi^{m}}\right)-\frac{\bar{\psi}}{j}\right]\right)$ is positive (or negative but small), then $\pi_{t}^{C 3}>\left(\pi_{t}^{B A S E}>\pi_{t}^{C 2} \geq \pi_{t}^{C 1}\right)$. This is due to the fact that the 'conflicting claims multiplier' (in this case $\left.\frac{1}{1-f h-[(1-\alpha) h d \varepsilon]-j \varepsilon[h e(1-\alpha)+\alpha(1-f h)]}\right)$ is larger than in the baseline case $\left(\frac{1}{1-f h-[(1-\alpha) h d \varepsilon]}\right)$.

As expected, real exchange-rate targeting leads to a higher inflation rate, but avoids (by construction) exchange-rate appreciation, thus favoring the manufacturing sector profitability (and allegedly avoiding or minimizing trade deficits). Indeed, since $n e r_{t}=-\bar{\psi}+j\left(w_{t}^{m}-\phi^{m}\right)$, it follows from equations (3), (6), and (13) that:

$$
\mu_{t}^{m, C 3} \equiv 0 .
$$

Whatever the inflation rate, in this case we obtain that $\mu_{t}^{m, C 3}>\mu_{t}^{m, C 2}>\mu_{t}^{m, B A S E}>\mu_{t}^{m, C 1}$. Finally, regarding the change in the profit share, we have:

$$
\begin{aligned}
b_{t}^{t o t, C 3}= & (1-\varepsilon)\left(\frac{1}{1-f h-[(1-\alpha) h d \varepsilon]-j \varepsilon[h e(1-\alpha)+\alpha(1-f h)]}\{[h e(1-\alpha)\right. \\
& +\alpha(1-f h)][a \bar{\rho}+b \bar{\chi}+c \bar{\psi}]+\left[h(1-\alpha)\left(g \tau+d \kappa \overline{\phi^{l}}-d \overline{\phi^{u n t}}\right)\right. \\
& \left.\left.+(1-\alpha)(1-h) \delta]+\left(j[h e(1-\alpha)+\alpha(1-f h)]\left[\left(\kappa \overline{\phi^{l}}-\overline{\phi^{m}}\right)-\frac{\bar{\psi}}{j}\right]\right)\right\}\right) \\
& +\alpha a \overline{\phi^{w}}+\alpha b \overline{\phi^{o p}}+\alpha c \overline{\phi^{m}}+\beta h \overline{\phi^{u n t}}+\beta \overline{i \phi^{\text {rnt }}-\kappa \phi^{l}} .
\end{aligned}
$$

Since $\pi_{t}^{C 3}>\left(\pi_{t}^{B A S E}>\pi_{t}^{C 2} \geq \pi_{t}^{C 1}\right)$, real exchange-rate targeting generates the worst functional distribution of income in the short run. Yet again, in the middle to long term, as this strategy seeks to preserve manufacturing's competitiveness, it need not give way to the same regressive outcome.

\subsection{Case 4: real exchange-rate targeting-cum-selective decoupling}

The combination of real exchange-rate targeting with selective decoupling also illustrates some real-world situations. In practice, most countries have intervened strongly in the currency markets at some point in order to moderate exchange-rate appreciation. Also, many have introduced some type of market intervention in commodity markets in order to make the domestic impact of the rise in international prices smaller.

Formally, the exchange-rate rule established in equation (30) in Case 3 (real exchange-rate targeting) needs to be combined with the commodity price formation rules established in equations (25) and (26) in Case 2 (selective decoupling) to obtain the following reduced form for the inflation rate:

$$
\begin{aligned}
\pi_{t}^{C 4}= & \frac{1}{1-f h}\{[h e(1-\alpha)+\alpha(1-f h)][a(1-\gamma) \bar{\rho}+b(1-\bar{\omega}) \bar{\chi}+c \bar{\psi}] \\
& \left.+\left[h(1-\alpha)\left(g \tau+d \kappa \overline{\phi^{l}}-d \overline{\phi^{u n t}}\right)+(1-\alpha)(1-h) \delta\right]\right\} \\
& +\frac{1}{1-f h}\left[(1-\alpha) h d \varepsilon \pi_{t-1}\right]+\frac{1}{(1-f h)}\{j[h e(1-\alpha)+\alpha(1-f h)] \\
& {\left.\left[\left(\kappa \overline{\phi^{l}}-\overline{\phi^{m}}\right)-\frac{\bar{\psi}}{j}\right]\right\}+\frac{1}{(1-f h)}\left\{[h e(1-\alpha)+\alpha(1-f h)] j \varepsilon \pi_{t-1}\right\} . }
\end{aligned}
$$


Once more, when $t \rightarrow \infty$ and the stability condition holds $(1>f h+$ $[(1-\alpha) h d \varepsilon]+j \varepsilon[h e(1-\alpha)+\alpha(1-f h)])$, we get:

$$
\begin{aligned}
\pi_{t}^{C 4}= & \frac{1}{1-f h-[(1-\alpha) h d \varepsilon]-j \varepsilon[h e(1-\alpha)+\alpha(1-f h)]}\{[h e(1-\alpha)+\alpha(1-f h)] \\
& {[a(1-\gamma) \bar{\rho}+b(1-\varpi) \bar{\chi}+c \bar{\psi}]+\left[h(1-\alpha)\left(g \tau+d \kappa \overline{\phi^{l}}-d \overline{\phi^{u n t}}\right)+(1-\alpha)\right.} \\
& \left.(1-h) \delta]+\left(j[h e(1-\alpha)+\alpha(1-f h)]\left[\left(\kappa \overline{\phi^{l}}-\overline{\phi^{m}}\right)-\frac{\bar{\psi}}{j}\right]\right)\right\} .
\end{aligned}
$$

It can be shown that $\pi_{t}^{C 2}<\pi_{t}^{C 4}<\pi_{t}^{C 3}$. That is to say, the combination of real exchangerate targeting with selective decoupling preserves the non-traditional tradable sector's competitiveness, but at a lower inflationary cost in relation to the case of pure real exchange-rate targeting (Case 3). This 'policy mix' bears a larger inflationary effect than the case of pure selective decoupling (Case 2), but selective decoupling does not preserve the non-traditional tradable sector's competitiveness.

The comparison remains indeterminate with respect to $\pi_{t}^{C 1}$ and $\pi_{t}^{B A S E}$, as in the case of $\pi_{t}^{C 2}$. One would expect that:

$$
\pi_{t}^{C 1}<\pi_{t}^{C 2}<\pi_{t}^{B A S E}<\pi_{t}^{C 4}<\pi_{t}^{C 3} .
$$

But, when inflation is to a large extent driven by international prices and these tend to weigh heavily on CPIs, inequality (37) may well be different, depending on the calibration of the selective decoupling coefficients $(\gamma$ and $\omega)$. If these coefficients are sufficiently large, so as to minimize the domestic impact of the rise in international primary goods prices $(\bar{\rho}$ and $\bar{\chi})$, then $\pi_{t}^{C 4}$ may well show up to the left of $\pi_{t}^{B A S E}$ :

$$
\pi_{t}^{C 2}<\pi_{t}^{C 1}<\pi_{t}^{C 4}<\pi_{t}^{B A S E}<\pi_{t}^{C 3} .
$$

It is also feasible - though unlikely - that $\pi_{t}^{C 4}<\pi_{t}^{C 1}$. Still, even if that were not the case, the combination of real exchange-rate targeting with selective decoupling is the only option that can preserve non-traditional tradable competitiveness while simultaneously exerting some control over the domestic impact of international inflation, since as in Case 3:

$$
\mu_{t}^{m, C 4} \equiv 0
$$

As regards the change in the profit share, we have that:

$$
\begin{aligned}
b_{t}^{t o t, C 4}= & (1-\varepsilon)\left(\frac{1}{1-f h-[(1-\alpha) h d \varepsilon]-j \varepsilon[h e(1-\alpha)+\alpha(1-f h)]}\{[h e(1-\alpha)+\alpha(1-f h)]\right. \\
& {[a(1-\gamma) \bar{\rho}+b(1-\varpi) \bar{\chi}+c \bar{\psi}]+\left[h(1-\alpha)\left(g \tau+d \kappa \overline{\phi^{l}}-d \overline{\phi^{u n t}}\right)+(1-\alpha)\right.} \\
& \left.\left.(1-h) \delta]+\left(j[h e(1-\alpha)+\alpha(1-f h)]\left[\left(\kappa \overline{\phi^{l}}-\overline{\phi^{m}}\right)-\frac{\bar{\psi}}{j}\right]\right)\right\}\right)+\alpha a \overline{\phi^{w}} \\
& +\alpha b \overline{\phi^{o p}}+\alpha c \overline{\phi^{m}}+\beta h \overline{\phi^{u n t}}+\beta \overline{i \bar{\phi}^{r n t}}-\kappa \overline{\phi^{l}} .
\end{aligned}
$$

Here the comparison runs parallel to that of inflation rates among the different cases. Higher inflation comes together with a larger profit share, so long as $\varepsilon<1$, so that $b_{t}^{\text {tot }, C 2}<b_{t}^{\text {tot }, C 4}<b_{t}^{\text {tot }, C 3}$. This is, by construction, a short-term result. However, in the medium to long term, the profit share is likely to increase more in cases where the 
Table 1 Different effects of the rise in international commodity prices on domestic inflation, external competitiveness, and income distribution, depending on the policy choice

\begin{tabular}{|c|c|c|c|}
\hline Scenarios & Inflation rate $\left(\pi_{t}\right)$ & $\begin{array}{l}\text { Reduction in manufacturing } \\
\text { sector markup } \\
\text { coefficient }\left(\mu_{t}^{m}\right)\end{array}$ & $\begin{array}{l}\text { Increase in profit } \\
\text { share }\left(b_{t}^{\text {tot }, C 4}\right)\end{array}$ \\
\hline Baseline & Moderate & Intermediate & High \\
\hline Case 1: XR appreciation & Low & High & $\operatorname{Low}(\mathrm{ST}), \operatorname{high}(\mathrm{MT})$ \\
\hline $\begin{array}{l}\text { Case 2: Selective } \\
\text { decoupling }\end{array}$ & Intermediate low $^{\mathrm{a}}$ & Low & $\begin{array}{l}\text { Intermediate (ST), } \\
\text { low (MT) }\end{array}$ \\
\hline $\begin{array}{l}\text { Case 3: Real XR } \\
\text { targeting }\end{array}$ & High & Nil & $\begin{array}{l}\text { High (ST), } \\
\text { intermediate (MT) }\end{array}$ \\
\hline $\begin{array}{l}\text { Case 4: Real XR } \\
\text { targeting-cum-selective } \\
\text { decoupling }\end{array}$ & Intermediate high $^{\mathrm{b}}$ & Nil & $\begin{array}{l}\text { Intermediate (ST), } \\
\text { low (MT) }\end{array}$ \\
\hline
\end{tabular}

Notes:

a. 'Intermediate low' here means lower than the baseline model but higher than in Case 1 .

b. 'Intermediate high' here means higher than Cases 1 and 2 (plus may be the baseline model) but lower than Case 3.

$\mathrm{ST}=$ short term; $\mathrm{MT}=$ medium term .

non-traditional tradable sector's profitability is under pressure, namely Cases 1 and 2, due to the medium-term effect of appreciated currencies on the likelihood of balanceof-payments crises.

\subsection{Comparative overview}

Table 1 summarizes results for the most relevant policy dimensions discussed in the paper, namely inflation, non-traditional (manufacturing) sector competitiveness, and functional distribution of income. There is no dominant strategy. Clearly, when confronted with rising international commodity prices, currency appreciation is the most effective antidote against inflation, with selective decoupling a second-best. Selective decoupling comes at the cost of higher inflation vis-à-vis currency appreciation, but is less harmful to the non-traditional sector's competitiveness. While in the short term the currency appreciation option generates a more progressive distribution of income than in the case of selective decoupling, in the medium to long term currency appreciation may result in a more regressive distributional impact due to insufficient capacity growth in the tradable sector. We infer this from actual experience as the model only deals with the short term. Real exchange-rate targeting has no negative effect on the non-traditional sector's competitiveness, but in the context of rising commodity prices comes at the cost of much higher inflation. Combining real exchange-rate targeting with selective decoupling preserves the aim of not hurting the non-traditional sector's competitiveness, but at a lower inflationary (and hence distributional) cost.

\section{CONCLUSIONS}

As in other developing regions, there has been a growing concern on the domestic inflationary impact of rising international commodity prices in Latin America (see, 
for example, Lora et al. 2011). In South America, where primary exports predominate, this inflationary drive coincided with the improvement in terms of trade. Resulting real exchange-rate appreciation throughout the region should not have come as a surprise - it is the expected effect of rising policy interest rates, as recommended by standard advice in the presence of rising inflation, and 'improved fundamentals. ${ }^{14}$ Naturally, low interest rates in advanced economies contributed to fuel this process from the 'supply side' (of international liquidity). What comes somewhat as a surprise is the coincidence of soaring terms of trade and worsening current-account balances.

This occurrence - a deteriorating foreign front - has shifted attention towards exchange-rate misalignment, both on 'orthodox' and 'new developmentalist' ranks. In both cases, albeit from different perspectives and with different emphases, contractionary fiscal policy seems to have been brought back to the fore - in the 'orthodox' case, as a second-best to monetary policy as an aggregate demand management tool (when further monetary tightening is likely to exacerbate exchange-rate misalignment); in the 'new developmentalist' case, as a necessary offsetting force to the expansionary side-effect built into exchange-rate market interventions aimed at thwarting currency appreciation.

The common concern about currency appreciation is warranted - and, given the region's history, welcome. So too as regards the apprehension about the inflationary effect of foreign-exchange market interventions, particularly in the context of rising commodity prices. The attention paid to aggregate demand growth as a relevant variable in dealing with inflation also seems sensible. But focusing exclusively on aggregate demand management in the fight against inflation does not seem all that reasonable, given the perceptible cost-push nature of the 'first-round' effects associated with the international commodity boom.

A new open economy 'impossibility trinity' or 'trilemma' seems to follow from our formal analysis, whereby only two of the following three objectives sought out domestic price stability, exchange-rate competitiveness, and income equality - could be attained. Indeed, in a world of rising international commodity prices, price stability and exchange-rate competitiveness can be attained simultaneously, but at the cost of worsening income distribution. This is a case where nominal wages are kept in check despite the growth in food prices. As a result, non-traditional tradable sector competitiveness is achieved via real wage contraction - and, as food weighs more heavily in the lower part of the wage pyramid, worsening of personal income distribution. This is the 'new developmentalist' case, which seeks to attain a trade surplus at the expense of domestic absorption. Price stability and income equality can also be attained simultaneously, yet again at the cost of exchange-rate competitiveness. This is the standard approach as supported by most international financial institutions. Finally, exchange-rate competitiveness and some equality in income distribution can be attained simultaneously, but at the cost of higher inflation. In this case policymakers seek to manage the exchange rate as an industrial policy tool, but not at the cost of a regressive distribution on income.

This trilemma cannot be fully overcome. But its implications can be amended. We argue that the concern with regard to the rise in inflation and the simultaneous emergence of apparent symptoms of 'Dutch disease' due to currency overappreciation

14. The following statement by the IMF (2011a) illustrates the point: 'Exchange rates should be allowed to continue to act as shock absorbers in the face of pressure stemming from economic conditions in the region that have improved more than those in more advanced economies, primarily because of terms-of-trade gains from high commodity export prices.'. 
cannot be tackled adequately if more audacious proposals concerning concrete market interventions are not brought to the fore. The purpose of this paper is precisely to show how these unconventional policy instruments, personified here via 'decoupling coefficients,' as applied in actual practice, ${ }^{15}$ can contribute to overcome the constraints posed by the impossibility trilemma as portrayed above.

\section{REFERENCES}

Abeles, Martín and Mariano Borzel (2010), 'El régimen bajo presión: Los esquemas de metas de inflación en Brasil, Chile, Colombia y Perú durante el boom en los precios internacionales de materias primas,' Documento de Trabajo No 31, Centro de Economía y Finanzas para el Desarrollo, Buenos Aires.

Arestis, Philip and Malcolm Sawyer (2013), 'Moving from Inflation Targeting to Prices and Incomes Policy,' Panoeconomicus, 1, 1-17.

Barbosa, Nelson (2008), 'Inflation Targeting in Brazil: 1999-2006,' in Epstein, G. and E. Yeldan (eds), Beyond Inflation Targeting: Central Bank Policy for Employment Creation, Poverty Reduction and Sustainable Growth, Cheltenham, UK and Northampton, MA: Edward Elgar, pp. 139-157.

Bernat, Gonzalo (2015), 'Tipo de cambio real y diversificación productiva en América del Sur,' serie Estudios y perspectivas, No 43 (LC/L.4031), June, Buenos Aires: Oficina de la CEPAL en Buenos Aires.

BIS (2011), Annual Report 2010/11, June, Basel.

Canavese, A. (1982), 'The Structuralist Explanation in the Theory of Inflation,' World Development, 10(7), 523-529.

ECLAC (2011a), 'Trends and Volatility in Agricultural Prices: Implications for Latin America and the Caribbean,' prepared for the G20 Study Group on Commodities, Buenos Aires, May.

ECLAC (2011b), Estudio Económico de América Latina y el Caribe 2010-2011, July.

Frenkel, Roberto (1984), 'Salarios industriales e inflación. El período 1976-1982,' Revista Desarrollo Económico 95.

Frenkel, Roberto (2008), 'Tipo de cambio competitivo, inflación y política monetaria,' Revista de Economía Política de Buenos Aires, Year 2, Vols 3 and 4, pp. 21-32.

Frenkel, Roberto and Jaime Ros (2006), 'Unemployment and the Real Exchange Rate in Latin America,' World Development, 34(4), 631-646.

Galindo, L. and J. Ros (2008), 'Alternatives to Inflation Targeting in Mexico,' in Epstein, G. and E. Yeldan (eds), Beyond Inflation Targeting: Central Bank Policy for Employment Creation, Poverty Reduction and Sustainable Growth, Cheltenham, UK and Northampton, MA: Edward Elgar, pp. 158-178.

IMF (2011a), World Economic Outlook, April 2011, Washington, DC.

IMF (2011b), World Economic Outlook, September 2011, Washington, DC.

Jones, D. and A. Kwiecinski (2010), 'Policy Responses in Emerging Economies to International Agricultural Commodity Price Surges,' OECD Food, Agricultural and Fisheries Working Papers, No 34, OECD Publishing.

Lavoie, Marc and Engelbert Stockhammer (2014), Wage-Led Growth: Concept, Theories and Policies, Conditions of Work and Employment Series No 41, Geneva: International Labour Organization (ILO).

Lora, Eduardo, Andrew Powell, and Pilar Tavella (2011), 'How Will the Food Price Shock Affect Inflation in Latin America and the Caribbean?', Inter-American Development Bank, Department of Research and Chief Economist, Policy Brief No IDB-PB-120, April.

Maynard, G. and W. van Ryckeghem (1976), A World of Inflation, London: Batsford.

15. For a comprehensive analysis of unconventional policy responses in developing countries to the recent rise in international commodity prices, see Jones and Kwiecinski (2010). 
Olivera, Julio (1967), ‘Aspectos Dinámicos de la Inflación Estructural,' Desarrollo Económico, $7(27), 261-266$.

Olivera, Julio H.G. (1973), 'Inflación estructural y el estructuralismo latinoamericano,' in Sunkel, O., G. Maynard, D. Seers, and J.H.G. Olivera (eds), Inflación y Estructura Económica, Buenos Aires: Paidós. (Originally published as Olivera, Julio H.G. (1964), 'On Structural Inflation and Latin American Structuralism,' Oxford Economic Papers, XVI(3), 321-332.)

Panigo, Demian and Pablo Chena (2011), 'Del neomercantilismo al tipo de cambio múltiple para el desarrollo. Los dos modelos de la posconvertibilidad,' in Panigo, Demian, Pablo Chena, and Norberto Crovetto (eds), Ensayos en honor a Marcelo Diamand. Las raíces del nuevo modelo de desarrollo argentino y del pensamiento económico nacional, Buenos Aires: Miño y Dávila/CEIL-PIETTE/Universidad Nacional de Moreno, pp. 241-268.

Perez Caldentey, Esteban and Matías Vernengo (2013), 'Is Inflation Targeting Operative in an Open Economy Setting?', Working Paper No 324, Political Economy Research Institute (PERI), University of Massachusetts, Amherst.

Seers, Dudley (1962), 'Theory of Inflation and Growth in Underdeveloped Economies Based on the Experience of Latin America,' Oxford Economic Papers, 14(2), 175-195.

Smithin, John (2011), 'Inflation,' in King, J.E. (ed.), A Handbook of Post Keynesian Economics, 2nd edn, Cheltenham, UK and Northampton, MA: Edward Elgar, pp. 288-294.

Sunkel, Osvaldo (1958), 'La inflación chilena: un enfoque heterodoxo,' El Trimestre Económico, 25(4), 570-599.

Taylor, Lance (1983), Structuralist Macroeconomics: Applicable Models for the Third World, New York: Basic Books.

Taylor, Lance (1988), Varieties of Stabilization Experience: Towards Sensible Macroeconomics in the Third World, Oxford and New York: Clarendon Press.

UNCTAD (2011), Trade and Development Report 2011, New York and Geneva: United Nations.

Vernengo, M. (2003), 'Balance of Payments Constraint and Inflation,' Working Paper No 06, Department of Economics, University of Utah. 